\title{
THE EFFECTIVENESS OF ACCESS TRAINING AND THE JOB OPPORTUNITIES SCHEME
}

\author{
Clare Dominick \\ Education and Training Support Agency
}

The effectiveness of labour market interventions aimed at improving the job prospects of individuals disadvantaged in the labour market has been questioned in the past and continues to be questioned today. Since the inception of ACCESS training, questions have been asked about its effectiveness both as a means of improving the job prospects of individuals disadvantaged in the labour market and as a means of skills development.

This paper summarises the results from a comparative evaluation survey in which the employment outcomes from three labour market interventions (ACCESS, Job Opportunities Scheme wage subsidy and the Job Seeker Register) were compared. Factors affecting employment outcomes are explored. Overall results indicated that participation in ACCESS training improved employment outcomes for certain groups. The Job Opportunities Scheme was also shown to improve individuals job prospects.

\section{Training Schemes}

This research compares the employment outcomes from three labour market interventions (ACCESS, Job Opportunities Scheme wage subsidy and the Job Seeker Register) in order to determine their relative effectiveness. The main focus of the research was on ACCESS training . The research was initiated in 1990 by the Department of Labour's Training Support Service, with involvement from the Labour Market Analysis Unit and NZES Review and Development unit. During the course of the research the Training Support Service became the Education and Training Support Agency (ETSA), a crown agency within the Education sector, which administers ACCESS training and other skills development programmes.

ACCESS began in 1987 as a training programme to improve the job prospects of people who were disadvantaged in the labour market and for whom traditional training methods were unsuitable or unavailable. Courses were run by a variety of training providers and decisions about funding courses were taken at a regional level. Training courses were selected according to the skill requirements of the local labour market and the previous performance of training providers. They covered a range of training provision, including life skills courses, vocational and work-based training. During 1990 over 70,000 people enroled in ACCESS training and over 13,000 attended courses at any one time.

The principal role of the NZ Employment Service (NZES) has been to provide nationwide placement services to employers and job seekers. The Job Seekers Register (JSR) contains the records of job seekers enroled with NZES. This helps match the job seeker to employer vacancies. People enroled can also gain access to NZES work experience schemes, job clubs and temporary job subsidy programmes. During 1990 between 150,000 and 175,000 people were registered as unemployed (excluding vacation workers) at any one time.

The Job Opportunities Scheme (JOS) wage subsidy provided temporary job subsidies to employers who hired job seekers registered with NZES for 15 weeks or longer or who were otherwise disadvantaged in the labour market. The aim was to assist disadvantaged job seekers gain fulltime ongoing waged employment, rather than casual shortterm jobs. Subsidies were negotiated with an employer and were variable in amount and duration.

\section{Concerns Prompting the Research}

During the 1990/1991 financial year \$157 million was spent on ACCESS training. Since its inception, questions were asked about its effectiveness both as a means of skills development and as a means of improving job prospects for disadvantaged individuals. The success of ACCESS was indicated firstly by the level of skill acquisition measured against the trainees' learning objectives, and secondly by the proportion of trainees in further training or education and in employment, one month after course completion. In 1990/91, one month after course completion, on average, $33 \%$ of trainees were in further training, and $22 \%$ were employed.

These indicators were criticised on a number of counts including the following:

${ }^{\circ}$ the time period between course completion and measurement of further training and employment outcomes is too short to accurately gauge the level of the labour market outcomes:

${ }^{\circ}$ the outcomes indicated effectiveness in absolute terms but did not give an indication of how effective the 
training was in relation to other schemes or to no intervention at all;

${ }^{\circ}$ the reliability of the outcomes and skill acquisitioninformation was questioned as it was assessed by training providers;

- there was little standardisation of the assessments between the courses and across regions.

The effectiveness of NZES Job Seeker Register (JSR) and the Job Opportunities Scheme (JOS) have also been questioned in the past. A matched group of JSR clients was included in the research primarily as a baseline comparison group. Whereas JOS was included firstly to provide information on participants longer-term labour market outcomes and secondly to compare the costeffectiveness of two labour market interventions (JOS and ACCESS).

\section{Research objectives and design}

The main objectives of the project were to:

$\circ$ ascertain longer-term (3 and 6 month) training and employment outcomes of ACCESS trainees;

${ }^{\circ}$ establish whether participation in ACCESS improves the job prospects of unemployed individuals;

${ }^{\circ}$ investigate what other factors affected the employment or further training outcomes;

- investigate what benefits ACCESS training has provided for ACCESS trainees;

- establish whether participation in JOS has lead to improved labour market prospects;

${ }^{\circ}$ consider whether the interventions assisted particular groups of individuals into employment;

- estimate the relative cost effectiveness of ACCESS training and the JOS wage subsidy option in improving the employment prospects of unemployed individuals.

The research involved a sample survey of ACCESS trainees, JOS and JSR clients with two face to face interviews during 1990. Individuals were not randomly allocated to groups but were randomly selected from each of the three populations. The sample design provided two independent regional samples, (but not a nationally representative sample).

The regions were the Waikato-Thames Valley and Canterbury (this region covers the Christchurch urban area and Rangiora only). They were selected to represent both urban and rural centres and both the North and South Islands. Regions in which the labour market was stagnant were not considered appropriate as the effect of the schemes could have been masked by low levels of labour market activity. The results cannot therefore be taken to indicate how effective the interventions might be in regions where the labour market was markedly depressed.

The net effect of training was evaluated by comparing outcomes of a sample of new entrants into ACCESS training with a matched sample of JSR clients. The net effect of JOS was evaluated by comparing the outcomes of a sample of JOS clients with a standardised group of JSR clients. Statistical analysis included the use of the tstatistic, chi-square and logistic regression. Poststratification procedures were applied in the comparison of ACCESS and JSR employment outcomes.

\section{Characteristics of the Survey Populations}

The survey populations comprised:

' all ACCESS trainees who commenced a course during Jan uary or February 1990;

${ }^{\circ}$ all individuals who were registered with NZES on 1 April 1990 (JSR).

- all individuals who commenced a JOS wage subsidy during January, February or March 1990.

The survey populations differed in age, sex, educational attainment and duration of registered unemployment. The ACCESS and JSR samples were matched on the basis of these four factors as they were liable to affect employment outcomes. Post-stratification was applied to the data in order that the remaining differences between the groups were taken into account. However in the event adequate post-stratification for the JOS-ACCESS comparison was not possible due to the large differences between respondents in the two samples.

The profiles of the three populations varied considerably, and there were differences between the regions, although to a lesser extent. The differences between the ACCESS and JSR populations were particularly marked for age, sex, education level, duration of registered unemployment and ethnicity. Those between ACCESS and JOS were considerable for ethnicity, sex and duration of unemployment.

Overall the ACCESS population had far greater female participation, had greater Maori and Pacific Island participation, were younger, were more educationally disadvantaged, and were registered with NZES for shorter periods of time.

\section{Response rates}

The response rates varied across regions and between the groups, and are detailed in Tables 1 and 2 . The response to the first survey was very satisfactory considering response rates from previous similar surveys. Difficulties were 
experienced in locating individuals, which accounts for the lower 'approach response rates' in the first survey. Once people were contacted their participation rate in the first survey was high, as was the response rate to the second survey.

\section{Characteristics of the Samples}

The ACCESS sample in each region, and in both surveys, closely resembled the original ACCESS populations, in terms of age, sex, educational level and duration of registered unemployment. The matched JSR samples also closely resembled the ACCESS population for age, sex and educational level, but there was some variation between the groups in relation to ethnicity, and work experience.

In both regions JSR respondents were more likely to have been either working or unemployed for most of the previous year, while the ACCESS group were more likely to have been in education or training. On average, the JSR respondents had spent longer in the work-force than the ACCESS respondents and had held a greater number of full time jobs.

The total length of ACCESS training for the year ranged from 1 to 27 weeks, with an average of 14 weeks. The first course attended (an average of 9 weeks) during 1990 was a vocational training course for $77 \%$; work-based training for $10 \%$; and a life-skills course for $12 \%$ of respondents.
Turning to the JSR sample, $16 \%$ attended ACCESS courses during 1990 after 1 April. The total length of ACCESS training undertaken during 1990 by this group averaged 9 weeks, although it ranged from 1 to 27 weeks.

JOS respondents were on average more advantaged than ACCESS trainees. Overall they were far more likely to be male; to be of European descent; to have had previous work experience; and to have educational qualifications.

\section{Employment Outcome Measures}

Three employment outcomes measures were used to assess the effectiveness of ACCESS in comparison with JSR:

a. whether an individual obtained employment during 1990 (after the first course undertaken for ACCESS and after 1 April for JSR);

b. the proportion of time an individual was employed during the follow-up period;

c. an individual's employment status at a particular point during the follow-up period.

To take into account the different characteristics of the ACCESS and JSR groups, the results were standardised to the ACCESS sample in each region. The unstandardised results are the raw survey data and give an indication of the actual level of employment for that population. The

Table 1. Response rates to the first survey by group and by region

$\begin{array}{lllll} & \begin{array}{l}\text { Waikato }- \text { T.V. } \\ \text { \% of all. } \\ \text { sought }\end{array} & \begin{array}{l}\text { \% of } \\ \text { contacted }^{2}\end{array} & \begin{array}{l}\text { Canterbury } \\ \text { \% of all } \\ \text { sought }\end{array} & \begin{array}{l}\text { \% of } \\ \text { contacted }\end{array} \\ \text { ACCESS } & 68 & 95 & 74 & 96 \\ \text { JSR } & 59 & 96 & 54 & 89 \\ \text { JOS } & 78 & 98 & 63 & 92\end{array}$

1 represents the number of successful interviews as a percentage of all individuals (within that particular region and group) who the research company tried to locate.

2 represents the number of successful interviews as a percentage of those people who were contacted by the research company.

Table 2. Response rates by group and by region for the second survey

\begin{tabular}{lrrrr} 
& Waikato-T.V. & Canterbury & \multicolumn{2}{c}{ Total Intended Total } \\
ACCESS & $93 \%(469)$ & $95 \%(483)$ & 952 & 1000 \\
JSR & $93 \%(288)$ & $94 \%(282)$ & 570 & 600 \\
JOS & $94 \%(188)$ & $94 \%(90)$ & 278 & 300 \\
Total & $\mathbf{9 4 5}$ & $\mathbf{8 5 5}$ & $\mathbf{1 8 0 0}$ & $\mathbf{1 9 0 0}$
\end{tabular}


standardised figures allow the two groups to be compared by adjusting for people's differing characteristics.

Measures (2) and (3) were used to compare JOS with either ACCESS or JSR. The ACCESS-JOS comparisons were unable to be standardised as there was little overlap between the two groups on important characteristics.

\section{ACCESS and JSR Employment Outcomes}

Measure 1 - getting a job. The standardised results show that more ACCESS than JSR respondents gained employment during the follow-up period. However the difference was significant for the Waikato-Thames Valley and not for Canterbury.

Measure 2 - time in employment. ACCESS respondents in both regions who gained employment spent, on average, a greater proportion of their time in employment compared with the JSR respondents. Both standardised and unstandardised results are statistically significant. This was the case when time spent in training by ACCESS respondents was taken into account (Table 4) and when it was not. The differences between JSR and ACCESS were also statistically significant when all respondents were compared (Table 5).

Measure 3- labour market status. Tables 6 and 7 show labour market status for the ACCESS and JSR groups at specific times. The JSR results were standardised to the ACCESS sample population. The regions have been combined, but, in general, employment outcomes were higher for Canterbury than for Waikato-Thames Valley.

The employment outcomes for the ACCESS group are consistently higher than for the JSR group, corroborating previous results. The gap closes somewhat with time, perhaps indicating that the beneficial effect on employment outcomes is strongest within the first six months.

Table 3. Proportion of respondents who obtained unsubsidised employment during the follow-up period - standardised and unstandardised

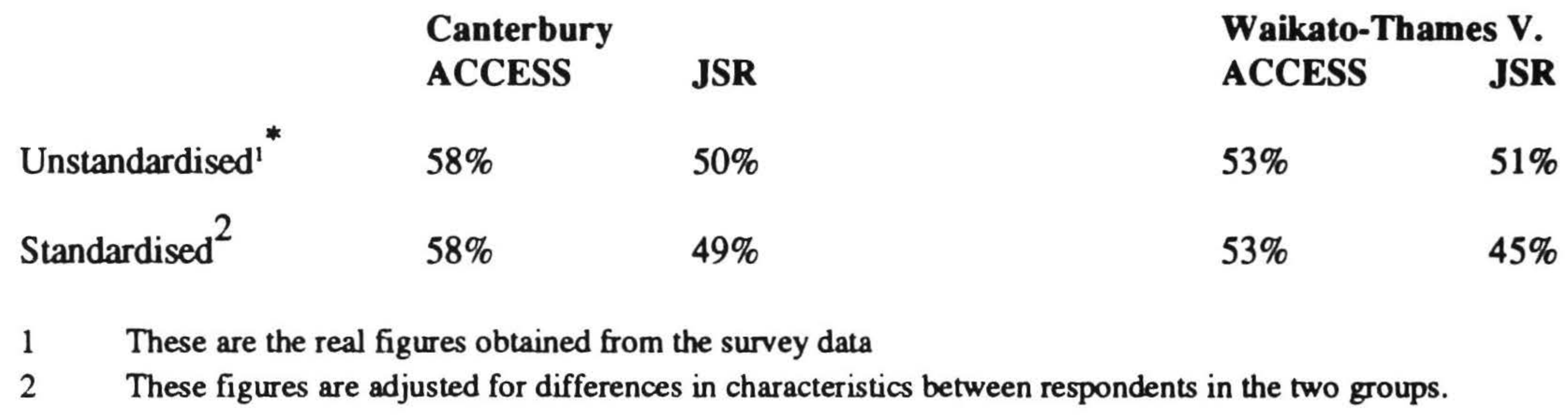

Table 4. Proportion of time spent in unsubsidised employment by those who obtained employment during follow-up period - standardised and unstandardised

\begin{tabular}{llllr} 
& $\begin{array}{l}\text { Canterbury } \\
\text { ACCESS }\end{array}$ & JSR & \multicolumn{2}{c}{ Waikato-Thames V. } \\
& $78 \%$ & $61 \%$ & $70 \%$ & ACCESS \\
Unstandardised & $78 \%$ & $57 \%$ & $70 \%$ & $56 \%$ \\
Standardised & $\mathrm{n}=212$ & $\mathrm{n}=94$ & $\mathrm{n}=203$ & $\mathrm{n}=111$ \\
& & & & \\
$\mathrm{n}=$ sample size & & &
\end{tabular}

Table 5. Proportion of time spent in unsubsidised employment during follow-up including respondents who did not gain employment

\begin{tabular}{lllll} 
& $\begin{array}{l}\text { Canterbury } \\
\text { ACCESS }\end{array}$ & JSR & \multicolumn{2}{c}{ Waikato-Thames V. } \\
& ACCESS & JSR \\
Unstandardised & $43 \%$ & $30 \%$ & $35 \%$ & $31 \%$ \\
Standardised & $43 \%$ & $30 \%$ & $35 \%$ & $26 \%$ \\
n = sample size & $\mathbf{n = 3 6 5}$ & $\mathbf{n = 1 9 2}$ & $\mathbf{n = 3 8 9}$ & $\mathbf{n = 2 2 6}$
\end{tabular}


Table 6. Total sample ACCESS - cross-sectional outcomes of labour market status one to six months after completing first course in 1990 (excludes subsidised employment)

Month

Employed ${ }^{\#}$

One

Two

Three

Four

Five

Six

* Percentages do not add to 100 due to rounding

" Unsubsidised employment
Labour Market Status (in percentages)

Unemployed

Training/
Education

Out of
Labour
Force

20
21
19
17
13
11

20
Total

100

100

$101^{*}$

$101^{*}$

99*

99*
Altematively, because the JSR results include respondents whoundertook training during the follow-up, the reduction in the gap may in part be due to this training.

\section{JOS and JSR Employment Outcomes}

Only two measures of employment outcomes were used to compare the JOS and JSR samples and these were not without complication. Measure 1 is not valid as by definition the JOS respondents obtained subsidised employment. The comparison of interest is whether and for how long JOS respondents remained in employment after the wage subsidy ended.

Unlike JOS participants, the JSR group were not assured a job, so comparison of the proportion of time spent in employment during the follow-up ought to be made only with those JSR respondents who obtained employment. (Approximately $50 \%$ of the JSR group obtained employment during the follow-up period.) This modified version of Measure 2 has been used in the JOS/JSR comparison.

Measure 2 - time in employment. Detailed below is a comparison of the proportion of time spent in employment by the JOS group subsequent to the subsidy cessation, with the proportion of time spent in employment by those in the JSR group who obtained employment during the follow-up period.

As can be seen from Table 8 JOS respondents were employed for a longer period of time after the subsidy ceased than JSR respondents were employed during the follow-up period. Standardising these results did not decrease the margin between the two groups.

Measure 3- labour market status. Table 9 shows the labour market status of the JOS group by month from the

Table 7. Total sample JSR - standardised cross-sectional outcomes of labour market status one to six months after 1 April 1990 (excludes subsidised employment)

Month

$$
\text { Employed }
$$$$
20
$$

One

Two

$$
23
$$

Three

Four

Five

Six

\section{Labour Market Status (in percentages)}

Unemployed Training/

$\begin{array}{ll}\begin{array}{l}\text { Out of } \\ \text { Education }\end{array} & \begin{array}{l}\text { Total } \\ \text { Labour }\end{array} \\ \text { Force } & \end{array}$

* Percentages do not add to 100 due to rounding.

Unsubsidised employment

1 Table 16 is standardised using educational level, ethnicity and number of full time jobs held (as one measure of work experience). 
Table 8. Proportion of time in employment (after the subsidy ceased - JOS respondents; JSR respondents who obtained employment)

$\begin{array}{lcc}\text { Group } & \text { JOS } & \text { JSR } \\ \text { Unstandardised } & 76 \% & 62 \% \\ & n=214 & n=206\end{array}$

start of the subsidy. Over half of JOS respondents received a subsidy for six months, therefore most of the employment outcomes recorded for months 'seven' and 'eight' were unsubsidised jobs.

Table 10 shows the standardised outcomes by month for the JSR sample. The results are standardised to the JOS sample over both regions. Even though the results are standardised there are considerable differences between the two groups. At six months $62 \%$ of JOS were in employment compared with $43 \%$ of JSR respondents.
However this gap is likely to narrow over time assuming the increase in JSR employment continues.

These results align with those from a Department of Labour study (unpublished) of longer-term outcomes of JOS respondents which indicates that approximately $60 \%$ of those who started a JOS wage subsidy job remained off the NZES job seeker register after two years.

\section{ACCESS and JOS employment outcomes}

As with the JSR JOS comparison, the comparison between ACCESS and JSR was made with the group of ACCESS respondents who obtained employment. Approximately $55 \%$ of the ACCESS group obtained employment during the follow-up period.

The unstandardised results from the two regions (see Table 11) are equivocal. The effective Waikato-Thames Valley sample was small and unlike the ACCESS-JSR comparisons the results across the two regions were

Table 9. Total sample JOS - cross-sectional outcomes of labour market status one to eight months after subsidy start

Month

Labour Market Status (in percentages)

\begin{tabular}{|c|c|c|c|c|c|}
\hline & Employed $^{\#}$ & Unemployed & $\begin{array}{l}\text { Training/ } \\
\text { Education }\end{array}$ & $\begin{array}{l}\text { Out of } \\
\text { Labour } \\
\text { Force }\end{array}$ & Total \\
\hline One & 83 & 15 & 1 & 1 & 100 \\
\hline Two & 78 & 18 & 2 & 3 & $101^{*}$ \\
\hline Three & 75 & 20 & 2 & 3 & 100 \\
\hline Four & 72 & 23 & 2 & 4 & $101^{*}$ \\
\hline Five & 69 & 25 & 2 & 4 & 100 \\
\hline Six & 65 & 28 & 3 & 4 & 100 \\
\hline Seven & 64 & 29 & 4 & 4 & $101^{*}$ \\
\hline Eight & 62 & 32 & 2 & 4 & 100 \\
\hline
\end{tabular}

* Percentages do not add to 100 due to rounding \# Includes subsidised and unsubsidised employment

Table 10. Total sample JSR - standardised to JOS ${ }^{1}$ cross-sectional outcomes of labour market status one to six months after 1 April 1990

Month

Labour Market Status

$\begin{array}{llll}\text { Employed } \quad \text { Unemployed } & \begin{array}{l}\text { Training/ } \\ \text { Education }\end{array} & \begin{array}{l}\text { Out of } \\ \text { Labour } \\ \text { Force }\end{array} & \text { Total } \\ & & \end{array}$

$\begin{array}{llllll}\text { One } & 26 & 66 & 5 & 3 & 100 \\ \text { Two } & 30 & 62 & 6 & 3 & 101^{*} \\ \text { Three } & 32 & 59 & 5 & 4 & 100 \\ \text { Four } & 36 & 54 & 6 & 4 & 100 \\ \text { Five } & 39 & 51 & 6 & 4 & 100 \\ \text { Six } & 43 & 46 & 7 & 4 & 100\end{array}$

*Percentages do not add to 100 due to rounding. 1.Standardised on the basis of educational level, sex and number of full time jobs held (as one measure of work experience). 
Table 11. Proportion of time spent in employment (after the subsidy ceased - JOS respond-

ents; ACCESS respondents who obtained employment) by region and group

\section{Canterbury Waikato-Thames V. ACCESS JOS ACCESS JOS}

Unstandardised $\mathbf{7 8 \%} \quad \mathbf{7 4 \%} \quad \mathbf{7 0 \%}$

$80 \%$

contradictory. In Canterbury the ACCESS respondents who obtained at least one job spent on average a greater proportion of their time in employment during the followup than the JOS respondents. The opposite was the case in the Waikato-Thames Valley. This may be explained to some extent by fact that the Waikato-Thames Valley ACCESS respondents had on average far greater labour market disadvantage than the JOS respondents. The small size of the Waikato-Thames Valley JOS group and the lack of overlap between the two groups on certain characteristics did notallow for adequate standardisation of the results by region .

Combined regional results indicate little difference between the two groups. (See Table 12). As for the regional comparison, the lack of overlap between the two groups on important characteristics did not allow for reliable standardisation of these results.

\section{Factors Affecting Outcomes}

The previous results indicated that ACCESS training improved an individual's chances of gaining and retaining employment. However, ACCESS training is only one of a number of factors that affected these chances. Education level, work experience, age, sex and ethnicity have already been noted as influential.

Overall variables which showed a statistically significant association with employment outcomes were work-based training; ethnicity; vocational training; previous work experience; recent labour market experience; education level; duration of registered unemployment and age.

\section{Course Type}

The analysis of ACCESS and JSR data indicated that ACCESS training was associated with significant increases

Table 12.Proportion of time spent in employment (after the subsidy ceased - JOS respondents; ACCESS respondents who obtained employment) by region and group

$\begin{array}{lcc}\text { Group } & \text { ACCESS } & \text { JOS } \\ \text { Unstandardised } & 75 \% & 76 \% \\ & \mathrm{n}=388 & \mathrm{n}=188\end{array}$

in the proportion of time spent in employment, where that training was either work-based or vocational. Workbased training values were consistently higher than those for vocational training. Both vocational and work-based training values were consistently higher than the JSR and life-skills training.

There were only small differences between JSR and ACCESS life-skills training in the predicted employment outcomes, although ACCESS life-skills training produced marginally higher predicted employment outcomes. This result and those for work-based and vocational training were consistent across several analyses. The low level of predicted employment outcomes from life-skills courses is mainly because these courses are seen as stepping stones into further education and training and this is reflected in training providers' contracts.

\section{Ethnicity}

Ethnicity was strongly associated with employment outcomes. Other characteristics being equal, the predicted values for Maori were in most instances substantially lower than for European. Exceptions occurred where individuals took work-based training and had also been either employed or in school/training for most of 1989. Predicted outcomes for Maori ACCESS respondents who had undertaken vocational or work-based training were in most instances substantially higher than JSR Maori respondents.

A number of factors may have contributed to the disparity between Maori and non-Maori. Many, such as educational level, previous work experience, duration of registered unemployment and type of training, were taken into account in the analysis. Two factors (job search behaviour and training provider type) which were shown to be associated with employment outcomes, were not included. However these two factors were associated and therefore confounded with, educational level and course type.

Manatu Maori (1990) discuss a number of factors which may contribute to the differential position of Maori and non-Maori in the labour market. These include age structure and population trends; geographical concentration; educational qualifications and intergenerational effects. They state that these factors cannot fully explain the difference between Maori and non-Maori and suggest that occupational segregation and discrimination in the labour market may also contribute. Age structure, geographical concentration and educational qualifications were to a large extent accounted for in this research, while occupational segregation, discrimination in the labour market and inter-generational effects were not.

\section{Education and Work Experience}

Educational qualifications, previous work experience and recent labour market experience were all statistically 
significant factors. Previous work experience (number of full-time jobs held), employment during most of 1989 and attending school/training during most of 1989 were positively associated with employment outcomes. Unemployment during most of 1989 and longer periods of registered unemployment were negatively associated with employment outcomes.

Age

Age was a statistically significant factor negatively associated with employment outcomes. Older age groups were predicted to have lower levels of employment outcomes, although the differences were not large.

\section{Who Benefits From ACCESS Training?}

In general results indicated that individuals on the margins of the labour market were assisted by ACCESS training. These individuals were those with:

- lower educational qualifications;

- Maori ethnicity;

- had been unemployed for most of 1989; and / or

- had little work experience.

Where all of these characteristics were present, the predicted levels of employment outcomes were not high, however in all instances they were higher than those predicted for their JSR counterparts.

For the most disadvantaged individuals, those who had all of the four characteristics listed above, an average of 14 weeks training was insufficient to improve their labour market prospects to a level that they were able to obtain and retain employment in a competitive labour market.

For the least disadvantaged, (that is those with factors positively associated with employment outcomes), there was little difference among work-based training, vocational training, life-skills training and JSR. For example, respondents with high educational qualifications, with substantial work experience, who had been employed for most of 1989 and who were European obtained high predicted employment outcomes, whether they had undertaken ACCESS training or not. For these individuals ACCESS training would not have added significantly to their employment prospects.

\section{Summary and conclusion}

Overall the results show that ACCESS training was effective in improving the employment prospects of disadvantaged individuals. Those most assisted by training were those who had lower educational qualifications; those who were Maori; those who were unemployed for extended periods; and those with litle work experience. Specific factors that increased individuals chances in the labour market were attendance at work-based or vocational training; active job search behaviour (often taught and assisted by training providers); higher levels of education and European ethnicity. Also important was knowledge of, and opportunity for, further training as well as the provision of links into the labour market by training providers.

These results show that a number of factors contribute to the effectiveness of training programmes. They also have implications for the effective targeting of labour market programmes and provide support for targeting training assistance to unemployed people with low skills and little work experience. However it does not suggest the need for severe targeting criteria as several factors either separately or in combination reduced individuals' chances in the labour market.

The successor to ACCESS, the Training Opportunities Programme aims to assist the most disadvantaged groups in the labour market. It will need to provide higher levels of assistance for this group to reach qualification and employment outcomes. The success of Training Opportunities will depend on the provision of linked courses through which trainees can progressively build on their skills and on the encouragement of more disadvantaged trainees to develop their skills in this manner.

\section{Notes}

1. A copy of the full report can be obtained from the National Office of the Education and Training Support Agency, P O Box 27-048, Upper Willis Street, Wellington.

\section{References}

Agresti, Alan. 1990 Categorical Data Analysis. John Wiley and Sons

Baker, Stephen. 1984 A Comparative Evaluation of the Impact on Participants of Selected Youth Labour Force Programs. (Working Paper No.50) - Bureau of Labour Market Research. Canberra, Australia.

Bertram, Geoff. 1988a Evaluation of employment programmes. A background paper in The April Report Vol 3 Part One Future Directions Associated Papers - Report of The Royal Commission on Social Policy 1988, Wellington.

Bertram, Geoff. 1988 Some Notes on Employment Programmes. (Paper for presentation to SSRFC/ NZIER Seminar "Social and Economic Policy" Wellington, Friday 1 July 1988) in Economic Policy and Social Policy Reform. - Proceedings of the Symposium. Sponsored by the Social Sciences Research Fund Committee. July 1988, Wellington.

Brooks, Clive. 1986 An Analysis of Factors Influencing the Probability of Transition from Unemployment to Employment for Australian Youth. (Working 
Paper No.63) - Bureau of Labour Market Research. Canberra, Australia.

Brooks, Clive and Volker, Paul. 1985 The Influence of Unemployment Duration and Heterogeneity on the Transition from Unemployment for Australian Youth. (Working Paper No.55) - Bureau of Labour Market Research. Canberra, Australia.

Brooks, Clive and Volker, Paul. 1983 Labour Market Success and Failure: An Analysis of the Factors Leading to the Workforce Destinations of the Australian Population (Conference Paper No. 38) - Bureau of Labour Market Research. Canberra. Australia

Callister, Paul. April 1990 Tomorrows Skills Revised Edition New ZealandPlanning Council, Wellington

Department of Statistics 1990. The New Zealand Labour Force December 1989 Quarter. Department of Statistics, Wellington, New Zealand

Department of Statistics 1991. The New Zealand Labour Force December 1990 Quarter. Department of Statistics, Wellington, New Zealand

Ginpil, Stephen and Hoy, Mavis. 1984 Some Factors Affecting the Completion Rates for Young People Under Wage Subsidy. (Working Paper No.46) Bureau of Labour Market Research. Canberra, Australia.

Haines, Lesley. 1989 Work Today: Employment Trends to 1989. New Zealand Planning Council. Wellington.

Kronenberg, N.; McRae, I. and Nicoll, P. 1985 The Australian Longitudinal Survey - Sample Design (Technical Paper No. 23)- Bureau of Labour Market Research. Canberra, Australia.

Lewis, E.T. and Ryan, Christopher A. 1985 Wage Subsidies, their employment effects and how to evaluate them (Working Paper No.51) - Bureau of Labour Market Research. Canberra, Australia.

Manatu Maori (Economic Development Unit). 1991 Maori and Work: The Position of Maori in the New Zealand Labour Market. Economic Development Unit Manatu Maori

McKay, Robyn and Hope, Catherine. 1986 Advances in the Evaluation of Labour Force Programs: Issues and Methodological Approaches, Bureau of Labour Market Research, Canberra.

McMahon, Pat and Robinson, Chris. 1984 Concepts, Definitions and Measures of Unemployment and the Labour Force. Are they appropriate for
Economic Policy Analysesin the 1980's? (Working Paper No.41) - Bureau of Labour Market Research. Canberra, Australia.

McRae, Ian. 1984 The Australian National Longitudinal Survey (Conference Paper No.44) - Bureau of Labour Market Research, Canberra, Australia.

Moir, Hazel V.J. and Robinson, Chris. 1982 Labour Market Measurement: A Review of Some Popular Labour Market Measures. (Working Paper No.5) Bureau of Labour Market Research. Canberra, Australia.

Muir, Jan. 1986 The First Wave of the Australian Longitudinal Survey: Facts and Figures about Young CES Registrants - Bureau of Labour Market Research, Blair Monograph Series No.12. Australian Government Publishing Service, Canberra.

Parkinson, G. and McRae, I. 1985 The Australian Longitudinal Survey - Questionnaire Design

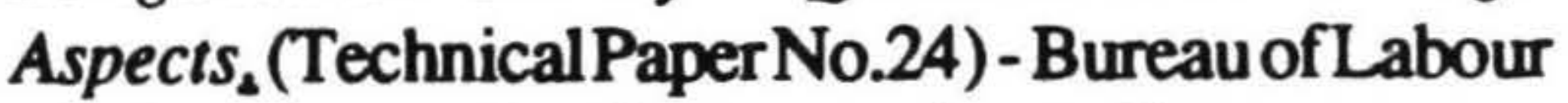
Market Research. Canberra, Australia.

Rao, G.L. (Bureau of Labour Market Research) and Jones, F.L. (Australian National University). 1986 Effectiveness of Youth Manpower Programs (Working Paper No.61) - Bureau of Labour Market Research. Canberra, Australia.

SAS Institute Inc. 1988 SAS Language Guide for Personal Computers, Release 6.03 Edition. Cary, NC:SAS Institute Inc

Savage, John. 1988 Links between Education and the Labour Market. NZ Institute of Economic Research. (Paper presented to an SSRFC seminar on Social and Economic Policy. 1 July 1988, Wellington)

Shirley, I., Easton, B. Briar, C., and Chatterjee, S. 1990 Unemployment in New Zealand, Dunmore Press

Skinner, C.J. Holt D. and Smith T.M.F. (1989)

Analysis of Complex Surveys. John Wiley and Sons, New York

Statistical Laboratory Iowa State University. $1986 P C$ CARP Wayne A. Fuller, Statistical Laboratory, Ames, IA 